\title{
Proposta de acolhimento diferenciado a pais de crianças com queixas de alterações de linguagem
}

\author{
Márcia Generoso Ribeiro ${ }^{1}$
}

Ribeiro MG. Proposta de acolhimento diferenciado a pais de crianças com queixas de alterações de linguagem [dissertação]. São Paulo: Pontifícia Universidade Católica de São Paulo; 2011.

Introdução: Tem sido crescente na clínica fonoaudiológica, no âmbito público ou privado a demanda por atendimento, a crianças com queixas como: "não fala", "fala pouco", "fala errado", ou "apresenta produções ininteligíveis". No Sistema Único de Saúde, a possibilidade de acolher essa demanda constitui-se uma questão relevante em conformidade com as políticas públicas de saúde, baseada nos conceitos de promoção, prevenção e acolhimento. Objetivo: Verificar a eficácia de um procedimento de acolhimento diferenciado, com fins preventivos, a pais de crianças com queixas de alterações de linguagem oral, que aguardam por atendimento fonoaudiológico no Sistema Único de Saúde. Métodos: Trata-se de pesquisa quanti-qualitativa. Participaram da pesquisa seis famílias em fila de espera numa UBS de de São Paulo. Foram utilizados cinco instrumentos: 1 . entrevista inicial com os pais; 2 . avaliação de linguagem; 3 . questionário de habilidades e dificuldades comunicativas dos pais; 4. protocolo de observação da atitudes comunicativas dos pais, preenchido a partir da filmagem de uma atividade lúdica entre pais e respectivos filho(a) e um instrumento que norteou a construção do acolhimento diferenciado; 5. ações favoráveis e desfavoráveis à comunicação, à brincadeiras e aos hábitos orais. Após três meses foram reaplicados os instrumentos 2, 3 e 4, para verificar se houve mudança. Resultados: Após o acolhimento diferenciado, todas as famílias referiram compreender melhor a fala das crianças. Observou-se aumento geral das atitudes comunicativas favoráveis do tipo: reformulações no discurso; enunciados de continuidade; solicitação de esclarecimento e decréscimo nas atitudes desfavoráveis. Isto evidenciou a repercussão positiva na dialogia, nas interações e consequentemente nas habilidades comunicativas dos filhos. Conclusão: Os resultados apontam que a proposta de acolhimento diferenciado foi efetiva como um dispositivo clínico fonoaudiológico em saúde pública, e que pode instituir novas práticas de atenção centradas na família e nos compromissos de co-responsabilidade entre profissionais de saúde e a população.

Trabalho apresentado ao Programa de Estudos Pós-Graduados em Fonoaudiologia, Pontifícia Universidade Católica de São Paulo - PUC-SP - São Paulo (SP), Brasil, para obtenção do título de Mestre em Fonoaudiologia, sob orientação da Profa. Dra. Sílvia Friedman.

(1) Programa de Estudos Pós-Graduados em Fonoaudiologia (Mestrado), Pontifícia Universidade Católica de São Paulo - PUC-SP - São Paulo (SP), Brasil. Endereço para correspondência: Márcia Generoso Ribeiro. R. Professor Agostinho Alvim, 88, Jd. do Colégio, São Paulo (SP), Brasil, CEP: 05883-140. E-mail: marciaribeirofono@gmail.com 